\title{
School Bullying Behavior among Adolescents in Palestinian Public Schools from their Teachers' Perspective
}

\author{
Majdi Jayousi ${ }^{1}$ \\ ${ }^{1}$ Educational Technology, Palestine Technical University, Palestine \\ Correspondence: Majdi Jayousi, Educational Technology, Palestine Technical University, Palestine
}

Received: April 21, 2020

Accepted: August 27, 2020

Online Published: August 28, 2020

doi:10.5539/mas.v14n9p37

URL: https://doi.org/10.5539/mas.v14n9p37

\begin{abstract}
The purpose of this study was to investigate the school bullying behavior among adolescents in public schools in the Qalqilya Governorate from the teachers' perspective in the first semester of the academic year (2018-2019). The study sample consisted of (240) teachers from the whole study population, which comprised 1200 teachers from public schools in the Qalqilya Governorate. The researcher used the descriptive research approach. A Questionnaire was used to measure school bullying behaviors. The questionnaire consisted of (30) sentences, divided into three domains. Its consistency and reliability were verified. the results of the study. Results showed that there were no statistically significant differences at the significance level of $(\alpha \leq 0.05)$ in the phenomenon of school bullying behavior among adolescents in public schools in the Qalqilya Governorate from the teachers' perspective due to the variable of gender. There were no statistically significant differences at the significance level of $(\alpha \leq 0.05)$ in the phenomenon of school bullying behavior among adolescents in public schools in the Qalqilya Governorate from the teachers' perspective due to the variable of the school. The study recommended the need to focus on teacher, counselor and trainer professional development to deal effectively with students' behavioral problems.
\end{abstract}

Keywords: bullying, school bullying, Palestinian schools

\section{Introduction}

The examination of adolescence is one of the most important criteria by which we measure community progress and development. Adolescence today is totally different from yesterday's world. We face more problems than our ancestors did. Therefore, parents and teachers should have different approaches to the adolescents and their problems (Mujahid , 2007). Adolescence indicates a longer period of time, and not just an ephemeral casual phase in human life. It is a transitional period from childhood to manhood (Mohamad, 2006). It is a period of transition from childhood to adulthood with unique characteristics (Rifai, 2014), forming more mature relationships of the same age level, achieving emotional independence of parents, and developing cognitive brainpower and problem-solving skills (Al-Bataishi,2009).

Adolescence is important for the teenager himself. Furthermore, parents can get aware of the physical and mental changes in their children's lives. As for teachers, they may be able to identify the characteristics of the adolescent (Mohamad, 2016).

believes that the transition from childhood (12-18 years old) to adulthood is most important. Adolescence constitutes a stage of processing, consolidation and integration. The teenager forms a self-image with meaning or value (Abdul Al Muharram,2016). At the stage of adolescence, teenagers build up their self-esteem and sense of identity; they also develop their religious values, adapt to physical changes, gain sexual orientation, accept their social responsibilities, explore personal skills and job options, form a value system for social roles, and prepare for marriage and family life (Al-Mashikhi, 2013 ).

There are three main features that make adolescence a distinct, unique and important stage, namely biological, cognitive, emotional and social changes. In fact, rapid changes in various aspects of life, including social, economic, cultural development, traditional and technological means of communication, and other daily complexities, led to greater impacts on the growth of violence and means of challenging it (Al-Sayed \& Alwan,2016) . Furthermore, research has shown that bullies are more likely to engage in antisocial and criminal behaviors during their adolescence and adult lives. (Taruna, 2017). 
School bullying behavior has prevailed all over the world for decades. High school leaders can use anti-bullying intervention strategies to address bullying behavior. 22\% of students aged (12-18) are being bullied. (Shannon, 2017)

Bullying is considered one of the forms of violence in school communities. It received greater attention in the 1960s by the Norwegian researcher Dan Olweus. Bullying is aggressive behavior, inflicted by an individual to another individual periodically or repeatedly, verbally or physically, directly or indirectly. (Al-Zoubi, 2015). School bullying is a universal problem that has negative repercussions on the general school settings that must have a safe learning environment free from intimidation. Bullying can have long-lasting effects on the lives of either the victim, perpetrator, or both (Adawi, 2014).

These include devastating effects of this phenomenon, especially on some students, like the increased risk of depression and anxiety, a sense of rejection, loss of interest in activities in school activities, and increased risk of suicidal thoughts and behaviors (Al-Qahtani, 2015). Besides, the bully can experience results like deprivation, expulsion from school, or non-access to educational programs (Abdul Jawad \& Ramadan, 2015).

Figures show that $50 \%$ of school-aged children experience bullying at some point in their school time.Children often hide their depression and anxiety because they feel ashamed or embarrassed. They should understand the nature of the problem so that they can deal with it and solve it (Ahmad \& Abdu, 2016).

Bullying can have physical, verbal or psychological types and forms. It can involve physical actions through words or in other ways and it can involve excluding people from groups or spreading lies or rumors (Aleem , 2016). Bullying may inflict harm or distress on the targeted youth, including physical, psychological, social, or educational harm (Kub \& Feldman, 2015).

Bullying can be the use of strength or status to intimidate others, inflict injury, or humiliate and intimidate another person who is weaker. There are many different types of bullying. It can be social, emotional, or physical (Alika , 2012). Bullying can be an attack or intimidation with the intention to cause fear, distress, or harm that is either: physical (e.g., hitting, punching), verbal (e.g., name-calling, teasing), or psychological/relational (e.g., rumors, social exclusion); a real or perceived imbalance of power between the bully and victim (Hertzog, Harpel, \& Rowley, 2016)

believes that there are four elements in bullying behavior regardless of gender and age. The first one is the imbalance of power. The second is the intention to cause harm and that the current aggression will continue, and tries to perpetrate bullying for extended periods. The cause of bullying is arrogance, contempt, disdain, not anger (Al-Abbasi , 2016).

Schools are commonly known to play a key role in maintaining the health of children and adolescents for over a century (Bani Younes, 2016). Bullying in schools is a common problem worldwide that has received great attention in recent years (Wei, Chang, \& et al, 2016). Bullying between students at school can seriously affect their social, physical and psychological wellbeing as well as their academic achievement (Cross, Monks, et al, 2011). School characteristics and climate are associated with students' academic and social outcomes, and whether they are likely to engage in bullying and aggressive behaviors (Hong \& Garbanino, 2012).

According to the American Psychology Dictionary, bullying is an aggressive behavior, directed towards others, especially those who are weaker (Ali, Abdul Al-Shafei, et al, 2015).

Traditional school bullying has been a growing concern for decades. $14.8 \%$ of students across the country had been bullied online through emails, chat rooms, instant messages, postings on websites, or mobile messages (Brewer, 2017)

School bullying affects the security, psychological and social wellbeing of the school community. Physical aggression inflicted by the perpetrators in schools cause harm to students at any educational level. It makes the victim feels rejected and undesirable, leading to a situation of fear, anxiety and uneasiness. The victim may withdraw from school activities or runs away from school. Additionally, the bully can face deprivation or expulsion from school, barriers to accessing to educational programs, and may engage in future serious criminal activities (Behansawi \& Hassan , 2015).

Researcher on bullying tend to focus on individuals involved in bullying at the expense of the social, institutional and societal context. They have shifted from previous understandings of bullying as coercion and control, and have instead sought to classify individuals involved into types (Horton, 2016).

Family factors are critical indicators of bullying behavior such as neglect and abuse (Al-Zahra \& Botaf, 2014) 
School factors: Respect between student and teacher has faded away at the expense of the teachers' dignity and control. In addition, there are no parallel activities at schools, and school life is limited to classroom activities (Awbari, 2014).

Bullying has several forms. In terms of means, direct bullying is a blatant attack on a target young man. It occurs between the people involved. Indirect bullying involves others about the bullied person. Moreover, there are three types of bullying behavior: verbal bullying, physical bullying, and relational bullying. Boys tend to use more direct bullying, whereas girls often get engaged in indirect bullying ( McClowry, Miller, et al, 2017).

Abdul Jawad and Al-Hussein (2015) suggest that direct bullying shows through direct confrontation between the bully and the victim. However, indirect bullying is subtle and harder to recognize, and can be inferred by observing its forms and can include lying and spreading rumors.

Verbal bullying includes using demeaning and humiliating language and comments (Hadiya, Abdul Latif, et al, 2016). Bullied students, even the quiet ones, can get angry because of the verbal insults more than any other form of bullying. Family pressure may play a role (Uzunboylu, Basak, et al, 2017).

Psychological bullying is a form of bullying in which verbal insults are not used. It involves facial expressions, spreading rumors, gossip, sedition, and other belittling behaviors (Hadiya, Abdul Latif, et al, 2016).

\subsection{Related Studies}

The study of Kyriacou, Keke, et al (2016) explored the extent to which a social pedagogic perspective is evident in the views of bullying in schools held by a sample of university students in England, Greece and Norway studying in the area of the education, care and welfare of children. A total of 469 university students completed a questionnaire in which they were asked to rate their strength of agreement with thirty statements concerning bullying in schools. The study found out that there was a general consensus amongst the respondents in all three countries that bullying was a major problem in schools and those schools were not tackling bullying adequately. The replies also indicated that many respondents reported views that aligned with a social pedagogic perspective. Differences between students within each country and between countries were in part a reflection of polarized views about how best to tackle bullying. The study suggested that the inclusion of social pedagogy in the professional education and training of pedagogic and care professionals might usefully help students to adopt a social pedagogic approach to prevent and tackle bullying in schools.

Williford, Boulton, \& et al (2016) examined the naturally-occurring changes in cognitive empathy during the transition from elementary to middle school. It also explored the effect of bullying and victimization involvement on changes in cognitive empathy over time, and specifically during this school transition. The study sample included 431 students. Latent growth curve modeling was used to examine growth trajectories in empathy over time and the effects of bullying involvement on this growth. The study found out that bullying and victimization were both associated with lower levels of cognitive empathy throughout the study. However, the effect of victimization was small and it became non-significant. The findings pointed to the potential to improve cognitive empathy skills and reduce involvement in bullying via preventive interventions prior to the transition from elementary to middle school to assist youth in making a more successful transition.

The study of Al-Sufi Al-Maliki (2012) examined bullying and its relationship to parental treatment style. The study sample consisted of 200 pupils. The researcher used the descriptive research methods. Two instruments were used. The first was to measure bullying and it included 19 items. To measure parental treatment, the researcher adopted a scale (Aletaby 2001). Statistical analysis showed that the correlation between bullying, wiggle and firm parental styles was statistically significant. Bullying was correlated negatively with 'neglect, careless, and authoritarian' parental styles. The study recommended the need to focus on school bullying educational programs and involve children in them, publish a diagnostic manual to help teachers identify and prevent bullying behavior and prevent bullying, and establish a safe bullying-free school environment.

The study of Wong, Cheng, et al, (2013) investigated the opinions of individuals in different roles (bullies, victims, bystanders, educators) regarding the targets and causes of bullying and to identify differences among various perspectives in Taiwan. A total of 1558 participants responded to the questionnaire. The researchers used a grounded-theory method to analyze qualitative data. The research found differences between the perspectives of educators and those of student participants regarding the causes of school bullying with respect to blaming the victims, the intentions of bullies, intolerance of diversity in peer cultures, and the influence of contextual factors. The study suggested that increasing awareness and minimizing these differences may help efforts to prevent and intervene in bullying. It suggested conducting further studies for a better understanding of the nature of school bullying. 
The study of (Mohamad 2014) explored the impact of a practical program on supporting and reducing symptoms of school bullying victims among a sample of students in the sixth grade. The study sample consisted of 18 students who have been chosen from two schools (Al-Abbas and Al-Ata). The sample was divided into two groups: the control group consisted of 9 students, and the experimental group consisted of 9 pupils. Data were analyzed statistically based on tests of (Wilcoxon) and (Mann Whitney) to measure the effect of the treatment in school bullying victims. Results showed that there were significant differences between the pre- and post-tests in favor of the experimental group after the application of the program. On the other hand, there were no significant differences in scores of pre- and post-tests of the control group. The study recommended the need to conduct more studies concerning treatment programs for different age groups and the need to focus on bullying prevention programs.

The study of (Ali \& Khudhair, 2015) aimed to assess the level of school bullying among victims of primary school pupils at AL-Nasiriyah City Center. This descriptive study used a questionnaire and was carried out on a purposive sample of 362 students in primary schools. The results of the study showed there was a strong level of bullying against primary school pupils, and that pupils demographic features have effects on them to be victims of school bullying. The study recommended the need to use effective world intervention programs to prevent and tackle bullying. It called for a more effective role of the school counselor and/or the social worker in addressing school bullying through working with the administration, teachers, students and parents.

The study of Balootbangan \& Talepasand, (2015) aimed to validate the Illinois bullying scale in primary school students in Semnan, Iran. In this study, 607 pupils were selected through the stratified sampling method. Research instruments included Illinois bullying scale and Harter's motivation questionnaire. For data analysis, factor analysis method, Cronbach's alpha coefficients, and Pearson correlations were used. They concluded that The Persian version of the Illinois bullying scale has acceptable psychometric properties and can be used as a reliable and valid instrument in psychological research. Bullying comprised three factors: bullying, victim and fighting. The validity of the bullying scale was high and acceptable. The study suggested that bullying construct was of great importance and it could be measured in other societies such as students, working environment, and even in the abstract world.

\subsection{Comment on Previous Studies}

The present study agreed with most of the previous studies regarding the variable of gender, including Balootbangan and Talepasand (2015), Muhamad (2014), and Ali and Khudhair (2015).

The present study agreed with most of the previous studies regarding the variable of the place of residence, including Balootbangan and Talepasand (2015), Muhamad (2014), and Ali and Khudhair (2015).

The present study is different from other studies by addressing the variables of qualification, school and teachers' age.

Previous studies have used different research methods. Some of them agreed with the analytical, descriptive approach of the present study, such as the study of Balootbangan and Talepasand (2015). The study of Muhamad (2014) and Ali and Khudhair (2015) used the experimental approach.

\subsection{The Problem of the Study}

Through educational visits to public schools, the researcher noticed that bullying behavior has become more prevalent in most public schools. He also noticed that there were scarce Arab studies, evidence and school-based studies on school bullying, which could provide enough information on bullying to educational institutions, especially schools. Adolescence is the most important stage for acquiring skills and building up the professional, ethical and academic personality of the individual. The researcher suggests that the high percentage of school bullying has negative consequences on the adequacy and quality of the educational process.

The stage of adolescence is a period of crises, in which many behavioral problems might turn into psychiatric, mental and behavior disorders such as delinquency, addiction, bullying or troublemaking (Alwan , 2016)

Bullying is most commonly defined as systematic, repeated, and intentional aggression. It has become a significant problem worldwide since it was first introduced by Olweus (1993). It can be a physical, verbal, or psychological attack or intimidation (Georgiou, Fousiani, \& et al, 2013). Bullying problem develops with students' age. Research showed that in Western countries, bullying behavior diminished before the students entered the middle school (grades 4 and 5), but increased after students entered middle school (grade 6) (Pan, Liu, \& et al, 2017) 
Bullying is a significant educational problem in many countries, and can impair schools' effectiveness (Kyriakides, Creemers, \& et al, 2014). Victims of bullying are lacking the qualities that ease with everyday social interactions and are incapable of the relaxed give and take of everyday life (Khouj, 2012).

Despite the seriousness of this problem in the Arab society, it has not yet received adequate study and attention in the Arab research literature. In contrast, many foreign books, research, and magazines examine bullying and even address bullying school prevention programs (Abdul Rahim, 2017).

The researcher emphasizes that the young victims of school bullying are characterized by many qualities that impair their normal growth and sound mental health, which affect their learning and academic achievement and their interaction with peers, family or school. They often suffer from disorders that have negative impacts on their growth.

Considering the information above, the study problem can be summarized in answering the following main question:

What is the prevalence of school bullying among adolescents in public schools in the Qalqilya Governorate?

\subsection{The Hypotheses of the Study}

Hypothesis I: There are no statistically significant differences at the significance level of $(\alpha \leq 0.05)$ in the phenomenon of adolescent bullying behavior in public schools in the Qalqilya Governorate due to the variable place of residence.

Hypothesis II: There are no statistically significant differences at the significance level of $(\alpha \leq 0.05)$ in the phenomenon of adolescent bullying behavior in public schools in the Qalqilya Governorate due to the variable of gender.

Hypothesis III: There are no statistically significant differences at the significance level of $(\alpha \leq 0.05)$ in the phenomenon of adolescent bullying behavior in public schools in the Qalqilya Governorate due to the variable of teacher qualification.

Hypothesis IV: There are no statistically significant differences at the significance level of $(\alpha \leq 0.05)$ in the phenomenon of adolescent bullying behavior in public schools in the Qalqilya Governorate due to the variable of the place of school.

Hypothesis V There are no statistically significant differences at the significance level of $(\alpha \leq 0.05)$ in the phenomenon of adolescent bullying behavior in public schools in the Qalqilya Governorate due to the variable of teacher's age.

\subsection{The Objectives of the Study}

- The phenomenon of adolescent bullying behavior in public schools in the Qalqilya Governorate from the teachers' perspective.

- The effect of the variables of the place of residence, gender, teacher's qualification, Type of school, and teachers' age, and their relationship to the phenomenon of bullying.

- The effect of the bullying school behavior on adolescents.

\subsection{The Significance of the Study}

\section{I: Theoretical significance}

The researcher emphasizes that the most notable aspects of the psychological lives of the adolescent students are their struggle for independence from their parents, tendency to become self-reliant adults, gradual elimination of adult authority and a sense of independence. Parents' approach to dealing with children has a profound effect on their behavior in the future. Some parents tend to use force and violence, and they also lack sufficient awareness of the nature of the adolescence. These parents tend to overlook mental and emotional demands of this phase, and thus their children often feel compelled to seek love and intimacy somewhere else. In this regard, peers play a more significant role in the lives of children and adolescents. Therefore, adolescents often resort to violence, rebellion, sabotage and offensiveness.

\section{II: Practical significance}

The results of this study suggest appropriate solutions to reduce the prevalence of the problem of bullying school among school-age children, the researcher notes that the bullying school is the school in which aggressive behavior prevails and is represented by an imbalance in strength where the student cannot exhibit aggression to 
defend himself. The study highlights some unhealthy individual characteristics and patterns of family relationships, which may help to identify students with a tendency to use bullying and thus avoid the emergence of the problem.

The study findings emphasize the importance of early prevention and detection of bullying behavior. It seeks to raise awareness among students, parents, mothers, and educators about the dangers of bullying behaviors and their future effects. It also develops plans to address bullying early at schools and in the educational field as a whole.

The findings of this study can be used to develop useful anti-bullying intervention programs and policies.

\subsection{Conceptual Definitions and Idioms}

Bullying can be defined as repeated aggressive behavior within a relationship characterized by a real or perceived imbalance of power, in which the student exposed to the aggressive actions cannot adequately defend him/herself (Cross, Monks, \& et al, 2011). Al-Juhani define bullying as a form of violence common amongst children and youth. It also refers to intentional harm or harassment by one or more individuals (Al-Juhani \& et al, 2014).

define bullying as a behavior that once was seen as normal, is currently a behavior that is shown to be a serious problem. There is a general agreement that for a behavior to be considered bullying, it must be repetitive (Choi, Cronin, \& et al, 2016).

School bullying is a set of repeated and intentional aggressive behavior, perpetrated by a person known as the bully against another person (bully-victim) with an intent to inflict harm within an unequal relationship or imbalance of power (Abu Al-Fadl \& Hassan, 2017).

The researcher defines school bullying is unwanted behavior that causes harm. The behavior is repeated, or has the potential to be repeated, over time. The bullies deliberately harass other students who are less powerful than them.

Adolescent: An individual who experiences a transitional phase of growth and development between childhood and adulthood, between 12-18. During Adolescence, the individual experiences physical and emotional changes (Zaghalil \& Al-Matarneh, 2011).

Adolescence: A middle stage between childhood and adulthood. It's a transitional phase, achieve independence and self-reliance (Abu Saad, 2010).

Adolescents are a group of people aged 15-18 (Khattab \& et al, 2012).

\subsection{The Limitations of the Study}

Place limitations: This study was conducted on the adolescent students in public schools in the Qalqilia Governorate.

Time limitations: This study was conducted during the first semester of the academic year (2018/2019).

Subject matter limitations: The study used an instrument, which was prepared by the researcher. Its consistency and reliability were verified. The findings of the study were generalized according to the validity and reliability of the research tool.

\section{Method and Procedures}

This chapter deals with the methods and procedures followed by the researcher in choosing the study sample and population. It describes the practical steps and procedures for the development of the study tool. It also explains the design and layout of the study and variables, in addition to statistical tests used in the study.

\subsection{The Methodology of the Study}

In light of the subject matter and collected data, the researcher used the descriptive, analytical method that best describes the reality of the problem in a quantitative and Quality manner. This approach is actually suitable for understanding the relational characteristics of the problem, as well as reaching conclusions and generalizations that can help to develop the situation under study.

\subsection{The Study Population}

The study population comprised all public-school teachers (1200) in the Qalqilya Governorate during the academic year 2018-2019 (Palestinian Ministry of Education). 
Table 1. Study sample according to its independent variables $(\mathrm{N}=222)$

\begin{tabular}{cccc}
\hline $\begin{array}{c}\text { Independent } \\
\text { variables }\end{array}$ & Variable levels & Number & Percentage (\%) \\
\hline \multirow{2}{*}{ Place of } & Village & 163 & 73.4 \\
residence & City & 59 & 26.6 \\
& Total & $\mathbf{2 2 2}$ & $\mathbf{1 0 0}$ \\
& Male & 134 & 60.4 \\
Gender & Female & 88 & 39.6 \\
& Total & $\mathbf{2 2 2}$ & $\mathbf{1 0 0}$ \\
& Diploma & 26 & 11.7 \\
Qualification & Bachelor & 164 & 73.9 \\
& Master & 32 & 14.4 \\
& Total & $\mathbf{2 2 2}$ & $\mathbf{1 0 0}$ \\
School & Males & 125 & 56.3 \\
& Females & 79 & 43.7 \\
& Total & $\mathbf{2 2 2}$ & $\mathbf{1 0 0}$ \\
& $20-30$ & 68 & 30.6 \\
Age & $31-40$ & 78 & 35.1 \\
& $41-50$ & 46 & 20.7 \\
& More than 50 & 30 & 13.5 \\
& Total & $\mathbf{2 2 2}$ & $\mathbf{1 0 0}$ \\
\hline
\end{tabular}

\subsection{The Sample of the Study}

The sample of the study was randomly selected from the study population. The sample consisted of 240 teachers ( $20 \%$ of the population). The number of the retrieved questionnaires was (232) of which 10 questions were excluded. Thus, the examined number of the study sample was (222). Table 1 shows the description of the sample of the study according to its independent variables.

2.3.1 The Instrument/Tool of the Study

After reviewing a number of previous studies and tools, the researcher developed a research tool to achieve the objectives of the study. The questionnaire comprised 30 items divided into 3 fields.

The researcher used the following steps:

- The questionnaire was presented to the raters.

- The questionnaire was initially modified according to the raters.

- The questionnaire was distributed among the respondents for data collection.

The questionnaire was designed on the basis of a literature review, and respondents were asked to respond to the 5-point Likert Scale

\section{Psychometric characteristics of the study tools:}

reliability of the study tool

The validity of the study tool was assessed through:

1. Content-related validity: To test and assess the content related reliability of the study tool (inter-rater reliability) and make sure that it serves the objectives of the study, it was presented to a group of specialist raters, thus the questionnaire was modified according to their notes.

2. The internal consistency of the questionnaire items (questions) was verified: The Pearson Correlation Coefficient (PCC) was used to verify the internal consistency of the study tool, making sure that the domains of the study were linearly related to each other and not overlapping. 
Table 2. Pearson test results of the domains of the study tool and different sections

\begin{tabular}{cc}
\hline Domains of the tool & Pearson Coefficient \\
\hline Behavioral domain & 0.81 \\
Educational domain & 0.75 \\
Psychological domains & 0.84 \\
Total Score & 0.82 \\
\hline
\end{tabular}

\section{Reliability of the research instrument}

The researcher measured the validity and reliability of the research instrument using the internal consistency which typically shows the correlations between different items on the same test. Cronbach Alpha was used to measure the coefficient of the internal consistency and estimate the reliability of test scores. Table 3 below shows the results of the Cronbach Alpha reliability coefficient test on the different domains for the study instrument.

Table 3. Results of the Cronbach Alpha reliability coefficient for the domains of the study instrument and its different sections

\begin{tabular}{cc}
\hline Domains of the instrument & Reliability coefficient value \\
\hline Behavioral domain & 0.82 \\
Educational domain & 0.83 \\
Psychological domain & 0.72 \\
Total Score & 0.81 \\
\hline
\end{tabular}

Table 3 shows that the value of the total score of the stability of the test scores was $(0.81)$ and it was reliable and suitable for research purposes.

\subsubsection{Procedures for Study Implementation}

In order to implement the study, the researcher conducted the study, according to the following steps:

1. Verifying the validity and reliability of the research instrument.

2. Obtaining official approval for data collection and distributing a questionnaire.

3. Identifying the respondents of the study sample.

4. Distributing and collecting research questionnaires.

5. Retrieving a total number of 232 questionnaires from the respondents.

6. Sorting out a total of 222 completed teacher questionnaires.

7. Classifying, encoding and entering data into the computer.

8. Statistically processing data.

\subsubsection{The Variables of the Study}

\section{Independent variables}

Place of residence: village, city.

Gender: Male Female.

Qualification: Diploma, BA, MA.

Type of school: Male, Female.

Age: 20-30, 31-40, 41-50, 50 and more.

\section{Dependent variables}

Dependent variables comprised respondents' views on the questionnaire items regarding school bullying among adolescents in public schools in the Qalqilya Governorate from the teachers' perspective. 


\section{Discussion of the study findings}

This section contains a full detailed presentation of the results of the study. Kolmogorov-Smirnov Test (1 sample K-S) was used to answer the questions of the study and validate its hypotheses, and ensure a normal distribution of the sample data. Also, statistical methods were used to test the hypotheses of the study.

Table 4 shows the results of the Kolmogorov-Smirnov Test which was used to determine whether the data followed the normal distribution or not and to test the hypotheses. Most laboratory tests require data distribution to be normal. The value of each of the study dimensions was greater than 0.05 . This indicates that the data follow the normal distribution and laboratory tests should be used.

Table 4. Natural distribution test (1 Sample K-S)

\begin{tabular}{ccc}
\hline Instrument & Test Value Z & Level \\
\hline Behavioral aspect & 1.04 & 0.94 \\
Educational aspect & 0.08 & 0.54 \\
Psychological aspect & 0.09 & 0.08
\end{tabular}

\section{Results of the Study}

The purpose of this study is to investigate the school bullying behavior among adolescents in public schools in the Qalqilya Governorate from the teachers' perspective and to determine the effect of the variables of the governorate, gender, job, qualification, and years of service. Collected data were statistically analyzed and processed using the SPSS. Here are the details of the major findings of the study.

\section{First: Results related to the first question:}

What is the prevalence of school bullying among adolescents in public schools in the Qalqilya Governorate from the teachers' perspective?

To answer this question, the arithmetic means, standard deviations, percentages and the degree of agreement on school bullying were used (Table 6).

To answer the question, the arithmetic means, percentages of all items and domains, and the total score of the questionnaire were used (Tables 6, 7,8).

In order to explain the results, the problem of school bullying among the teenagers in public schools in the Qalqilia Governorate from the teachers' perspective was assessed through measuring the arithmetic means of the responses. The five-point scale $(5-1=4)$ was calculated then the range was divided by the number of categories to determine the length of the category $(4 / 5=0.80)$. The first category was $(1+0.80=1.80)$, and then $(0.80)$ was added to each category as follows (Abu Dalal, 2010).

1. The arithmetic mean (1-1.80) or (less than $36 \%$ ) indicates a very low degree.

2. The arithmetic mean (1.81 -2.60) (36.1\% - 52\%) indicates a low degree.

3 . The arithmetic mean (2.61 - 3.40) (52.1\% - 68\%) indicates an average degree.

4. The arithmetic mean (3.41 - 4.20) (68.1\% - 84\%) indicates a significant degree.

5 . The arithmetic mean (4.21 - 5) (more than $84 \%$ ) indicates a very high degree. 


\section{Behavioral domain}

Table 5 shows the arithmetic means and percentages of school bullying among adolescents in public schools from the teachers' perspective in the behavioral domain by the degree of agreement sorted in the descending order.

\begin{tabular}{|c|c|c|c|c|c|c|}
\hline $\begin{array}{l}\mathscr{D} \\
\mathbb{D} \\
\stackrel{0}{0} \\
0 \\
0 \\
0 \\
0\end{array}$ & $\begin{array}{l}\underset{\vec{\rho}}{\Xi} \\
Z \\
\end{array}$ & Item & SMA & SD & $\%$ & 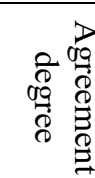 \\
\hline 1. & 1 & Students mock each other. & 3.89 & 1.03 & 77.8 & high \\
\hline 2. & 8 & Some students mock other students & 3.84 & 0.97 & 76.8 & high \\
\hline 3. & 3 & Students say swearwords to each other & 3.81 & 0.67 & 76.2 & high \\
\hline 4. & 2 & Some students disturb others during activities & 3.73 & 1.02 & 74.6 & high \\
\hline 5. & 6 & Some students call others by unkind names. & 3.73 & 1.20 & 74.6 & high \\
\hline 6. & 9 & Some students intentionally hurt students' feelings. & 3.65 & 0.99 & 73 & high \\
\hline 7. & 5 & Some students are beaten by other students. & 3.59 & 0.67 & 71.8 & high \\
\hline 8. & 4 & Some students take and hide other students' things. & 3.55 & 1.05 & 71 & high \\
\hline 9. & 7 & Some students threaten each other inside the school. & 3.54 & 1.34 & 70.9 & high \\
\hline 10. & 10 & Students dislike snitching (informing) on others. & 3.54 & 0.06 & 70.9 & high \\
\hline \multicolumn{3}{|c|}{ Total score } & 3.65 & 1.4 & 73 & high \\
\hline
\end{tabular}

* The highest degree for item (5)

Table 5 shows that the scores of the prevalence of school bullying among adolescents in public schools were high across all items. The percentage of respondents' responses to this item was $77.8-70.9 \%$. The total score was high. The average value of the percentage of the respondents' responses to all items was $73 \%$.

\section{Educational domain}

Table 6 shows the arithmetic means and percentages of school bullying among adolescents in public schools from the teachers' perspective in the educational domain by the degree of agreement sorted in the descending order.

\begin{tabular}{|c|c|c|c|c|c|c|}
\hline 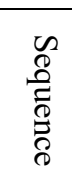 & $\begin{array}{l}\overrightarrow{\vec{\Phi}} \\
\Xi \\
Z \\
\end{array}$ & Item & SMA & SD & $\%$ & 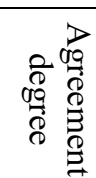 \\
\hline 1 & 20 & $\begin{array}{l}\text { Observation of students at the school playground, courtyard, } \\
\text { toilets, and corridors. }\end{array}$ & 4.19 & 0.963 & 83.8 & high \\
\hline 2 & 11 & $\begin{array}{l}\text { You think that mass media like TV and the Internet play a } \\
\text { role in increasing bullying behavior among the students. }\end{array}$ & 4.13 & 1.004 & 82.6 & high \\
\hline 3 & 15 & $\begin{array}{l}\text { Organizing awareness lectures on violent behaviors and } \\
\text { tackling them. }\end{array}$ & 4.1 & 1,23 & 82 & high \\
\hline 4 & 17 & $\begin{array}{l}\text { Building good relationships between parents and school } \\
\text { counselor. }\end{array}$ & 4.03 & .994 & 80.6 & high \\
\hline 5 & 16 & $\begin{array}{l}\text { The teacher reaches an amicable solution to the problem } \\
\text { between the students. }\end{array}$ & 4.02 & 1,23 & 80.4 & high \\
\hline 6 & 14 & $\begin{array}{l}\text { School is one of the most important institutions that affect } \\
\text { student behaviors. }\end{array}$ & 3.97 & .987 & 79.4 & high \\
\hline 7 & 12 & $\begin{array}{l}\text { You expect the parents' educational and cultural level to play } \\
\text { a role in school bullying. }\end{array}$ & 3.92 & .987 & 78.4 & high \\
\hline 8 & 19 & $\begin{array}{l}\text { The school counselor suggests solutions for teachers to } \\
\text { prevent school bullying. }\end{array}$ & 3.92 & 1.78 & 78.4 & high \\
\hline 9 & 13 & You think that the bully is a low achiever. & 3.68 & 1.98 & 73.6 & high \\
\hline 10 & 18 & $\begin{array}{l}\text { The bullying student must be temporarily dismissed from his } \\
\text { school. }\end{array}$ & 3.5 & 1.05 & 70 & high \\
\hline \multicolumn{2}{|c|}{ Total score } & & 3.94 & 0.564 & 78.8 & high \\
\hline
\end{tabular}

* The highest degree for item (5) 
Table 6 shows that the prevalence of school bullying among adolescents in public schools was high (items 1-10). The percentage of respondents' responses was (70.0-83.8\%). The total score was high. The average value of the percentage of the respondents' responses to all items was $78.8 \%$.

\section{Psychological domain}

Table 7 shows the arithmetic means and percentages of school bullying among adolesicents in public schools from the teachers' perspective in the psychological domain by the degree of agreement sorted in the descending order.

\begin{tabular}{|c|c|c|c|c|c|c|}
\hline 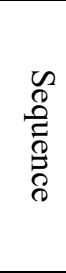 & $\begin{array}{l}\overrightarrow{\overrightarrow{0}} \\
\stackrel{\Xi}{Z} \\
Z \\
\end{array}$ & Item & SMA & $\mathrm{SD}$ & $\%$ & 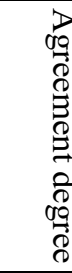 \\
\hline 1 & 22 & $\begin{array}{l}\text { Family disintegration plays a role in increasing student } \\
\text { aggressive school behavior. }\end{array}$ & 4.25 & 1.09 & 85 & high \\
\hline 2 & 23 & $\begin{array}{l}\text { Disruptive behavior is more frequent during the adolescence } \\
\text { period. }\end{array}$ & 4.10 & 1.03 & 82 & high \\
\hline 3 & 30 & $\begin{array}{l}\text { The student exhibits bullying behavior to draw the attention } \\
\text { of teachers and peers. }\end{array}$ & 4.07 & 0.98 & 81.4 & high \\
\hline 4 & 26 & $\begin{array}{l}\text { Depriving a student of his basic needs leads to aggressive } \\
\text { behavior. }\end{array}$ & 3.95 & 0.345 & 79 & high \\
\hline 5 & 25 & A student's lack of confidence increases bullying behavior. & 3.89 & 1.03 & 77.8 & high \\
\hline 6 & 24 & $\begin{array}{l}\text { A teacher's mistreatment of a student plays a role in his } \\
\text { aggressive behavior. }\end{array}$ & 3.85 & 1.09 & 77 & high \\
\hline 7 & 29 & Student's lack of self-confidence increases bullying behavior. & 3.82 & 0.98 & 76 & high \\
\hline 8 & 21 & $\begin{array}{l}\text { Striking and reprimanding a student by an adult play role in } \\
\text { his disruptive behavior. }\end{array}$ & 3.75 & 0.082 & 75 & high \\
\hline 9 & 28 & $\begin{array}{l}\text { The absence of a student's parent or both parents increases } \\
\text { aggressive behavior. }\end{array}$ & 3.65 & 1.09 & 73 & high \\
\hline 10 & 27 & $\begin{array}{l}\text { The low financial level of the student intensifies his bullying } \\
\text { behavior }\end{array}$ & 3.55 & 1.03 & 71 & high \\
\hline \multicolumn{3}{|c|}{ Total score } & 3.89 & & & 1.5 \\
\hline
\end{tabular}

* The highest degree for item (5)

Table 7 shows that the prevalence of school bullying among adolescents in public schools from the teachers' perspective was very high in item (1). The percentage of respondents' responses to these items was $85 \%$. The agreement degree for items (2-10) was high, and the percentage of respondents' responses to these items was $(82-71 \%)$. The total degree is high too. The average value of the percentage of the respondents' responses to all items was $77.8 \%$.

\section{Results of the study hypotheses}

\section{Results of the first hypothesis:}

There were no statistically significant differences at the significance level of $(\alpha \leq 0.05)$ in the phenomenon of school bullying behavior among adolescents in public schools in the Qalqilya Governorate from the teachers' perspective due to the variable of the place of residence.

In order to test the hypothesis, the researcher used the T-test for two independent groups as shown in Table 8. 
Table 8. T-test results showing the differences in the arithmetic means of the scores of adolescent bullying due to the variable of the place of residence.

\begin{tabular}{ccccccc}
\hline $\begin{array}{c}\text { Place of residence } \\
\text { Domains }\end{array}$ & $\begin{array}{c}\text { Village } \\
\text { Mean }\end{array}$ & $\begin{array}{c}\mathrm{N}=163 \\
\mathrm{SD}\end{array}$ & $\begin{array}{c}\text { City } \\
\text { Mean }\end{array}$ & $\begin{array}{c}\mathrm{N}=95 \\
\mathrm{SD}\end{array}$ & $\begin{array}{c}\text { t-calculated } \\
\text { calculated }\end{array}$ \\
\hline Behavioral Domain & 3.65 & .087 & 3.58 & 1.2 & 2.9 & .090 \\
Educational Domain & 3.88 & 1.06 & 4.1 & 0.006 & .068 & .974 \\
Psychological Domain & 3.81 & 1.12 & 4.10 & 1.06 & .642 & .424 \\
Total score & 3.87 & 0.09 & 3.93 & 1.11 & 1.993 & .159
\end{tabular}

* Statistically significant at level $(\mathrm{a} \leq 0.05)$

Table 8 shows that the calculated p-value of the variable of the place of residence in the total score is $(0.159)$, which is higher than the $p$-value of the study $(a \leq 0.05)$. Thus, the researcher accepts the hypothesis that there are no differences in the prevalence of bullying behavior among adolescent students. The researcher attributes this finding to the fact that youths acquire school bullying from their surrounding environment and community, and that students imitate each other, especially during adolescence in which many changes occur. Most school-aged children use bullying as defending behavior against the surrounding influences. Indeed, the adolescence period and its changes are not related to the variable of the place of residence (village or city). The finding is consistent with the studies of Muhamad (2014), and Ali and Al-Khudhair (2015).

Results of the second hypothesis:

There were no statistically significant differences at the significance level of $(\alpha \leq 0.05)$ in the phenomenon of school bullying behavior among adolescents in public schools in the Qalqilya Governorate from the teachers' perspective due to the variable of Place of residence.

In order to test the hypothesis, the researcher used the T-test for two independent groups as shown in Table 9.

Table 9. T-test results showing the differences in the arithmetic means of the scores of adolescent bullying due to the variable of Place of residence.

\begin{tabular}{ccccccc}
\hline Place of residence & $\begin{array}{c}\text { Village } \\
\text { Dean }\end{array}$ & $\begin{array}{c}\mathrm{N}=163 \\
\mathrm{SD}\end{array}$ & $\begin{array}{c}\text { City } \\
\text { Mean }\end{array}$ & $\begin{array}{c}\mathrm{N}=95 \\
\mathrm{SD}\end{array}$ & $\begin{array}{c}\mathrm{t} \text {-calculated } \\
\text { calculated }\end{array}$ \\
\hline Behavioral Domain & 3.76 & .859 & 3.45 & 1.03 & 2.621 & 107. \\
Educational Domain & 3.87 & .935 & 4.05 & 1.7 & 3.55 & .061 \\
Psychological Domain & 3.78 & 631. & 4.05 & 1.87 & 1.98 & .016 \\
Total score & 3.8 & 1.2 & 3.85 & 1.7 & .133 & 016. \\
\hline
\end{tabular}

* Statistically significant at level $(\mathrm{a} \leq 0.05)$

Table 9 shows that the calculated p-value of the variable of gender in the total score is $(0.016)$, which is higher than the $p$-value of the study $(a \leq 0.05)$. Therefore, the researcher declines the hypothesis that there are no differences in the prevalence of bullying behavior among adolescent students due to the variable of gender. Consequently, according to the This statistics is not suitable for t-testthere are differences in favor of males. The researcher attributes this finding to the fact that boys' and girls' reactions to various situations are different. Young boys tend to use more violent actions, swearwords, and physical force than girls. The finding is consistent with the studies of Muhamad (2014), and Ali and Al-Khudhair (2015).

\section{Results of the third hypothesis:}

There were no statistically significant differences at the significance level of $(\alpha \leq 0.05)$ in the phenomenon of school bullying behavior among adolescents in public schools in the Qalqilya Governorate from the teachers' perspective due to the variable of teacher qualification.

In order to test the hypothesis, the researcher used the T-test for two independent groups as shown in Tables10-11. 
Table 10. Arithmetic means of the phenomenon of school bullying among adolescent students in the Qalqilya Governorate due to the variable of teacher qualification.

\begin{tabular}{llll}
\hline Place of residence & Diploma & BA & MA \\
\multicolumn{1}{c}{ Domains } & Mean & Mean & Mean \\
\hline Behavioral Domain & 0.867 & 0.76 & 0.83 \\
Educational Domain & 0.013 & 1.23 & 0.88 \\
Psychological Domain & 0.8 & 0.16 & 0.873 \\
Total score & 0.52 & 0.26 & 0.373 \\
\hline
\end{tabular}

* Statistically significant at level $(\mathrm{a} \leq 0.05)$

Table 10 shows that there are differences between the arithmetic means. The One-Way ANOVA Test was used to determine whether these differences reached the level of the statistical significance (Table 13).

Table 11. Results of the One-Way ANOVA of the significant differences in the phenomenon of school bullying among adolescent students in the Qalqilya Governorate due to the variable of teacher qualification

\begin{tabular}{|c|c|c|c|c|c|c|}
\hline Qualification & $\begin{array}{l}\text { Source of } \\
\text { variations }\end{array}$ & $\begin{array}{l}\text { Sum of } \\
\text { Squares }\end{array}$ & $\begin{array}{l}\text { Degree of } \\
\text { Freedom }\end{array}$ & $\begin{array}{c}\text { Mean of } \\
\text { Deviation }\end{array}$ & F-Calculated & p-value \\
\hline \multirow{3}{*}{$\begin{array}{c}\text { Behavioral } \\
\text { Domain }\end{array}$} & Between Groups & .696 & 2 & .348 & .427 & .653 \\
\hline & Within Groups & 178.641 & 219 & .816 & & \\
\hline & Total & 179.337 & 221 & & & \\
\hline \multirow{3}{*}{$\begin{array}{c}\text { Educational } \\
\text { Domain }\end{array}$} & Between Groups & 2.425 & 2 & 1.214 & 3.626 & .028 \\
\hline & Within Groups & 73.316 & 219 & .335 & & \\
\hline & Total & 75.743 & 221 & & & \\
\hline Psychological & Between Groups & .696 & 2 & .497 & 1.243 & .291 \\
\hline \multirow[t]{2}{*}{ Domain } & Within Groups & 178.641 & 219 & .400 & & \\
\hline & Total & 179.337 & 221 & & & \\
\hline \multirow[t]{3}{*}{ Total Score } & Between Groups & 1.22 & 2 & 0.207 & 2.11 & .124 \\
\hline & Within Groups & 63.336 & 219 & 0.289 & & \\
\hline & Total & 64.557 & 221 & & & \\
\hline
\end{tabular}

* Statistically significant at level $(\mathrm{a} \leq 0.05)$

Table 11 shows that the calculated p-value of the variable of qualification in the total score is $(0.124)$, which is higher than the $\mathrm{p}$-value of the study $(\mathrm{a} \leq 0.05)$. Therefore, we accept the hypothesis that there are no differences in the prevalence of bullying behavior among adolescent students due to the variable of teacher qualification. However, this acceptance does not necessarily mean absolute acceptance because it is a double-sided finding. Therefore, it seems that there are no significant differences due to the variable of teacher qualification. The researcher attributes this finding to the fact that school bullying behavior is not pertinent to the teacher qualification. It is rather related to the nature of the youth group and adolescence.

\section{Results of the fourth hypothesis:}

There were no statistically significant differences at the significance level of $(\alpha \leq 0.05)$ in the phenomenon of school bullying behavior among adolescents in the public schools in the Qalqilya Governorate from the teachers' perspective due to the variable of school.

In order to test the hypothesis, the researcher used the T-test for two independent groups as shown in Table 12. 
Table 12. T-test results showing the differences in the arithmetic means of the scores of adolescent bullying due to the variable of school.

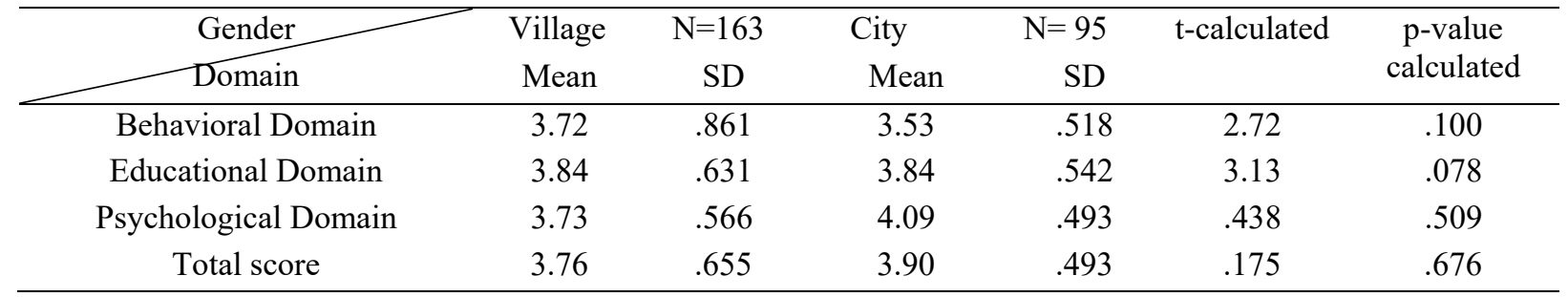

* Statistically significant at level $(\mathrm{a} \leq 0.05)$

Table 12 shows that the calculated p-value of the variable of school in the total score is $(0.676)$, which is higher than the $\mathrm{p}$-value of the study $(\mathrm{a} \leq 0.05)$. Therefore, we accept the hypothesis that there are no differences in the prevalence of bullying behavior among adolescent students due to the variable of school. The researcher attributes this finding to the fact that the type of school (girls, boys or mixed) does not have an effect on students' behavior. These personal behaviors are not associated with the type of school. Thus, bullying is widespread in single-sex and/or co-educational schools.

\section{Results of the fifth hypothesis:}

There were no statistically significant differences at the significance level of $(\alpha \leq 0.05)$ in the phenomenon of school bullying behavior among adolescents in the public schools in the Qalqilya Governorate from the teachers' perspective due to the variable of teacher's age.

In order to test the hypothesis, the One-Way ANOVA of the significant differences of the phenomenon of school bullying among school-aged students in the Qalqilya governorate due to the variable of teacher's age Tables 13-14.

Table 13. Arithmetic means of school bullying among adolescents in public schools in the Qalqilya governorate due to the variable of teacher's age.

\begin{tabular}{ccccc}
\hline Age & $\begin{array}{c}31-40 \\
\text { Dean }\end{array}$ & Mean & $\begin{array}{c}41-50 \\
\text { Mean }\end{array}$ & $\begin{array}{c}\text { 51 more } \\
\text { Mean }\end{array}$ \\
\hline Behains & 0.867 & 0.76 & 0.873 & 0.76 \\
Educational Domain & 0.013 & 1.23 & 0.88 & 1.23 \\
Psychological Domain & 0.8 & 0.16 & 0.873 & 0.16 \\
Total score & 0.52 & 0.26 & 0.373 & 0.373 \\
\hline
\end{tabular}

Table 13 shows that there are differences between these arithmetic means. The One-Way ANOVA Test was used to determine whether these differences have a statistical significance ( $p$-value) (Table 15).

Table 14. Results of the One-Way ANOVA of the significant differences in the phenomenon of school bullying among adolescents in public schools in the Qalqilya governorate due to the variable of teacher's age.

\begin{tabular}{|c|c|c|c|c|c|c|}
\hline Age & $\begin{array}{l}\text { Source of } \\
\text { variations }\end{array}$ & $\begin{array}{l}\text { Sum of } \\
\text { Squares }\end{array}$ & $\begin{array}{l}\text { Degree of } \\
\text { Freedom }\end{array}$ & $\begin{array}{c}\text { Mean of } \\
\text { Deviation }\end{array}$ & F-Calculated & p-value \\
\hline \multirow{3}{*}{$\begin{array}{l}\text { Behavioral } \\
\text { Domain }\end{array}$} & Between Groups & 2.76 & 3 & \multirow{3}{*}{$\begin{array}{l}1.580 \\
.801\end{array}$} & \multirow{3}{*}{1.973} & \multirow{3}{*}{.119} \\
\hline & Within Groups & 11.34 & 218 & & & \\
\hline & Total & 631.456 & 221 & & & \\
\hline \multirow{3}{*}{$\begin{array}{l}\text { Educational } \\
\text { Domain }\end{array}$} & Between Groups & 2.76 & 3 & \multirow{3}{*}{$\begin{array}{l}.315 \\
.343\end{array}$} & \multirow{3}{*}{.917} & \multirow{3}{*}{.433} \\
\hline & Within Groups & 11.34 & 218 & & & \\
\hline & Total & 631.456 & 221 & & & \\
\hline \multirow{3}{*}{$\begin{array}{c}\text { Psychological } \\
\text { Domain }\end{array}$} & Between Groups & 3 & 2 & \multirow{3}{*}{$\begin{array}{l}1.550 \\
.786\end{array}$} & \multirow{3}{*}{4.028} & \multirow{3}{*}{.008} \\
\hline & Within Groups & 218 & 219 & & & \\
\hline & Total & 221 & 221 & & & \\
\hline \multirow{3}{*}{ Total Score } & Between Groups & 3 & 2 & \multirow{3}{*}{$\begin{array}{l}1.456 \\
.567\end{array}$} & \multirow{3}{*}{3.285} & \multirow{3}{*}{.022} \\
\hline & Within Groups & 218 & 219 & & & \\
\hline & Total & 221 & 221 & & & \\
\hline
\end{tabular}

* Statistically significant at level $(\mathrm{a} \leq 0.05)$ 
Table 14 shows that the calculated p-value of the variable of school in the total score is $(0.022)$, which is higher than the $p$-value of the study $(a \leq 0.05)$. Therefore, we reject the zero hypothesis that there are no differences in the prevalence of school bullying among adolescents due to the variable of teacher's age. The researcher attributes this finding to the fact that bullying behavior among school-aged children is largely related to the teacher's age. In the past times, students paid due respect to their teachers and schools. Nowadays, however, students have become more aggressive towards teaching staff as a result of technological development and globalization. Scheffe test results were in favor of the age group 31-40.

\section{Recommendations}

In light of the study findings, the researcher recommends the following:

- Raising awareness among teachers on tackling school bullying.

- Enhance teacher, counselor and teacher trainer professional skills to effectively handle students' behavioral problems before they become insurmountable.

- Raising public awareness through parents' and teachers' councils about the optimal pedagogical methods of child rearing to deter bullying or aggressive behavior.

- Creating a safe and supportive school environment that can help prevent and strictly monitor bullying behavior.

- Conducting further studies to help ameliorate the bullying problem and understand the nature and extent of school bullying.

\section{Acknowledgment}

I would like to thank Palestine Technical University- Kadoorie for providing support.

\section{References}

Abu Al-Fadl, M, \& Yasser, H. (2017). The Effectiveness of a Selective Counseling Program on Developing Emotional Intelligence and Its Effect on School Bullying of Second Stage of Basic Education Pupils with Hearing Disabilities. Special Education Journal, Educational, psychological and environmental information center, Faculty of Education, Zagazig University, Egypt, Vol. 18, pp 28-32.

Abu Dalal, H. (2010). Trade unions and their role in the political development in Palestine. Unpublished Master Thesis, Al-Azhar University. Gaza, Palestine.

Abu Saad, M. (2010). Annoying Adolescents. Ebdaa Fekry Publishing, Al-Safa, Kuwait, Ed. 1.

Abdul Jawad, Wafa, \& Hussein, Ramadan. (2015). Family climate and its relationship to school bullying among primary school students. Psychological Counseling Journal, Egypt, Vol. 3, no. 42. P. 4.

Abdul Rahim, Mohamad. (2017). The Role of Technical Secondary School Principals in Sharkia Governorate in Confronting School Bullying, from Teachers' Point of View. Journal of Arab Studies in Education and Psychology, Saudi Arabia, no. 85. P. 289.

Abdul Al, Muharram, \& Lashin, Thuraya, et al. (2016). School climate and its relationship to school bullying among a sample of prepartory stage students (government - private). Journal of Educational and Social Studies, Egypt, 22(3), 676.

Adawi, T. (2014). Factorial structure of the bullying victimization scale among a sample of primary school students. Journal of Scientific Research in Education, Egypt, 2 (15), 573.

Ahmad, Kamel, Abdu, Saad. (2016). School bullying and its relationship with moral intelligence for the preparatory stage pupils: Predictive study. Faculty of Graduate Studies of Education, Cairo University.

Aleem, Sheema. (2016). Bullying Behavior Among School Students: A Review. Indian Journal of Health and Wellbeing, Vol. 7, No. (10). p. 978

Ali, Mohammad, Khudhair, Ali (2015). Level of School Bullying among Victims of Primary School Students at AL Nasiriya City Center. Journal of University of Thi-Qar, 10 (3).

Alika, Henrietta (2012). Bullying as a Correlate of Dropout from School among Adolescents in Delta State: Implication for Counselling. Nigeria, Faculty of Education, University of Benin, 132(3), 523-531.

Ali, Emad, Abdul Al-Shafei, Wafa, et al. (2015). Linguistic disorders as indicators of school bullying among people with mental developmental disorders. Journal of the Faculty of Education, Assiut, Egypt, 31( 4), 212. 
Al-Juhani, Raja et al. (2014). Self-esteem and bullying among a sample of hyperactive students. Journal of Scientific Research in Education, Egypt, 4(15), 186.

Al-Zoubi, Reem (2015). Awareness Degree of Female Trainees to the Causes of Bullying Among Students in the First Three Grades and the Procedures of Addressing it. Journal of QOU for Educational and Psychological Research and Studies, Palestine, 3(12).

Al-Sufi, O, \& Fatima Al-Maliki (2012). Bullying and its Relationship to Parental Treatment Style. Journal of Educational and Psychological Research, 35, 149.

Al-Abbasi, Ghasaq (2016). Behavior of bullying among pupils of the primary stage and the students of the middle stage according to the variables of gender and birth order. Journal of Educational and Psychological Research, 50, 93.

Al-Qassimi, Mahra, Al-Shamsi, Aisha (2013). Development and growth of children and the requirements of stages. Al -Ward Island Library, Cairo, Egypt, 2nd ed. p. 77.

Al-Qahtani, Norah. (2015). The Extent of elementary Female Teachers Awareness about Bullying and Actual Measures Followed to Prevent It in Government Schools in Riyadh from their Perspective. Arab Studies in Education and Psychology (ASEP), Saudi Arabia, 58, 80.

Al-Mashikhi, Ghalib (2013). Basics of Psychology. Dar Al Masirah, Amman, Jordan, Ed. 1, P. 88.

Al-Musawi, Abdul Aziz. (2013). Growth Psychology and its Theories. Dar Al-Redawn for Publishing and Distributing, Amman, Jordan, 1st ed., p. 171.

Alwan, Emad. (2016). Forms of bullying in the light of demographic variables among adolescent students in Abha City. Journal of Education (Al-Azhar University), 1(168), 442.

Awbari, Al-Hussein. (2014). School bullying: its causes and treatment. New education https://www.new-educ.com/intimidation-scolaire.

Austin, Shelia, Reynolds, Glenda, et al. (2016). SCHOOL LEADERSHIP AND COUNSELORS WORKING TOGETHER TO ADDRESS BULLYING. Reading Improvement, 53(4), 191.

Balootbangan, Afzal, Talepasand, Siavash. (2015). Validation of the Illinois bullying scale in primary school students of Semnan, Iran. Journal of Fundamentals of Mental Health, 17(4).

Bani Younes, Mohamad. (2016). Emotional conditions of the bullying students compared to nonbullying students. Association of Arab Universities Journal for Education and Psychology, Syria, 14(1).

Behansawi, Ahmad, Hassan, Ramadan. (2015). School bullying and its relationship with the achievement motivation among the preparatory stage pupils. Journal of the Faculty of Education, Port Said, Egypt, 17, 14.

Brewer, Steven. (2017). Addressing youth bullying through the whole child model education, 138(1), 44.

Cross, Donna, Monks, Helen, et al. (2011). Three-year results of the Friendly Schools whole ${ }^{-}$of $^{-}$school $^{-}$ intervention on children's bullying behavior. British Educational Research Journal, 37(1), 106. https://doi.org/10.1080/01411920903420024

Choi, Kyung, Cronin, Shea, et al. (2016). The assessment of capable guardianship measures against bullying victimization in the school environment. Routledge Taylor \& Francis Group. Police Practice and Research, 150. https://doi.org/10.1080/15614263.2015.1128161

Ertesvag, S (2016). Students who bully and their perceptions of teacher support and monitoring. British educational research Journal, 42(5), 829. https://doi.org/10.1002/berj.3240

Georgiou, S., Fousiani, Kyriaki, et al. (2013). Cultural value orientation and authoritarian parenting as parameters of bullying and victimization at school. Routledge Taylor \& Francis Group. International Journal of Psychology, 48(1), 70. https://doi.org/10.1080/00207594.2012.754104

Graham, Sandra (2016). Victims of bullying in schools. The Ohio State University's College of Education and Human Ecology, 137. https://doi.org/10.1080/00405841.2016.1148988

Gumpel, Thomas, Vered, Koren, et al. (2014). An ethnographic study of participant roles in school bullying. Aggressive behavior, 40, 216. https://doi.org/10.1002/ab.21515

Hadiya, Fuad, Abdul Latif, Sherine, et al. (2016). The Effectiveness of a Counseling Program in Reducing Bullying Among A sample of Deaf Teenagers. Childhood Studies, Egypt, 19(73), 113. 
Hertzog, Jodi, Harpel, Tammy. (2016). Is It Bullying, Teen Dating Violence, or Both? Student, School Staff, and Parent Perceptions, 38(1), 22. https://doi.org/10.1093/cs/cdv037

Hong, Jun, Garbanino, James. (2012). Risk and Protective Factors for Homophobic Bullying in Schools: An Application of the Social-Ecological Framework. Educational Psychology Review, 275. https://doi.org/10.1007/s10648-012-9194-y

Horton, Paul. (2016). Portraying Monsters: Framing School Bullying through a Macro Lens. studies in the cultural politics of education, 37, 204. https://doi.org/10.1080/01596306.2014.951833

Jenkins, Lyndsay, Mulvey, Nichole, et al. (2017). Social and Language Skills as Predictors of Bullying Roles in Early Childhood: A Narrative Summary of the Literature. Education and treatment of children, 40(3), 409. https://doi.org/10.1353/etc.2017.0017

Khalsa, Al-Bataishi (2009). Adolescence: its concepts and its various psychological, physical and emotional needs. Education Message. Sultanate of Oman, 24, 18-25.

Khattab, Iman et al. (2012). Cinematic therapy of adolescence issues. Journal of Scientific Research in Faculty of Women for Arts, Ain Shams University, Egypt, 13, 314.

Khouj, Hanan (2012). School Bullying and its Relationship to Social Skills in Primary School Students in Jeddah, Saudi Arabia. Journal of Educational and Psychological Sciences, 13(4), 202. https://doi.org/10.12785/JEPS/130407

Kub, Joan, Feldman, Marissa. (2015). Bullying Prevention: A Call for Collaborative Efforts between School Nurses and School Psychologists. Wiley periodicals, Psychology in the schools, 52(7), 661. https://doi.org/10.1002/pits.21853

Kyriacou, Chris, Keke, Iro, et al. (2016). Social pedagogy and bullying in schools: the views of university students in England, Greece and Norway. British Educational Research Journal, 42(4). https://doi.org/10.1002/berj.3225

Kyriakides, Leonidas, Creemers, Bert et al. (2014). Improving the School Learning Environment to Reduce Bullying: An Experimental Study. Routledge Taylor \& Francis Group. Scandinavian journal of educational research, 58(4), 454. https://doi.org/10.1080/00313831.2013.773556

Mahmoud, Mohamad. (2016). The efficiency of a counseling program for social intelligence skills development in reducing the behavior of bullying school among primary school pupils. Al-Hikma Journal for Educational and Psychological Studies, Kounouz Al-Hekma for Publishing \& Distribution, Algeria, 7, 292.

McClowry, Robert, Miller, Marshal, et al. (2017). What family physicians can do to combat bullying. Department of Family and Community Medicine, Sidney Kimmel Medical College at Thomas Jefferson University, Philadelphia. P. 83.

Mehta, Sharmila, Cornell, Dewey, et al. (2009). Validity of Three School Climate Scales to Assess Bullying, Aggressive Attitudes, and Help Seeking. School Psychology Review, 38(3), 339.

Mohamad, Asmaa. (2014). The impact of a practical treatment program in enabling victims of bullying among a sample of 6th graders. College of Education for Women - Educational \& Psychological Sciences Department, Baghdad University, 25(1), 73.

Mohamad, Ayman. (2006). Adolescence: The most critical stage of life. Taiba For Printing, Giza, Egypt, 1st ed. p. 8.

Mujahid, Fatima. (2006). Effectiveness of an educational program in alleviating the intensity of rebellious behavior among secondary stage students: A comparative study. Second Scientific Conference, the Arab Society for Information Technology and Education System, Cairo, Egypt, 5-6 July 2007.

Nazir, Tehseen, Nesheen, Falak. (2016). Impact of school bullying on psychological well-being of adolescents. Indian Journal of Health \& Wellbeing, 6(10), 1037.

Pan, Y., Liu, H., et al. (2017). A latent transition analysis of bullying and victimization in Chinese primary school students. PLOS ONE, 12(8), 2. https://doi.org/10.1371/journal.pone.0182802

Rifai, Adel. (2014). Problems of adolescence and methods of treatment problems (Achievement - family behavior - psychology). Konoz, Cairo, Egypt, Ed. 1, P. 11.

Sakran, Al-Sayed, Alwan, Emad (2016). The Factorial Structure of the Phenomenon of School Bullying as an Integrative Concept, the Ratio Spread and Its Justifications among Public Education Students in Abha. 
Special Education Journal - Educational, Psychological and Environmental Information Center, Faculty of Education, Zagazig University, Egypt, 16, 5.

Shatibi, Fatima Al-Zahra, \& Ali Botaf (2014). The reality of bullying in the Algerian schools: Middle stage: A field study. Psychological Studies, Al-Baseera Center for Educational Studies and Consultations, Algeria, 11,75 .

Shannon, Tory. (2017). Bullying in Secondary Schools: Action Planning Using a Positive Behavior Intervention and Support Framework. American Secondary Education, 45(2), 85.

Sims, Trevin, Kameya, Darren. (2016). Responding to school bullying in modern times, leadership is the property of association of California School Administrators. 26.

Taruna, Yadav. (2017). A review of factors affecting school bullying. Guides, Projects, Research for Teaching method. Indian Association of Health, Research and Welfare, 8(5), 395.

Uzunboylu, Huseyin, Baglama, Basak, et al. (2017). Opinions of school counselors about bullying in Turkish high schools. Social behavior and personality, 45, 1050. https://doi.org/10.2224/sbp.6632

Vahedi, Shahram, Azar, Eskandar, et al. (2016). The effectiveness of school-wide anti bullying programs on teachers' efficacy in dealing with students' bullying behavior. Journal of Fundamentals of Mental Health, $18(2)$.

Wei, Hsi-Sheng, Chang, Heng-Hao, et al. (2016). Bullying and Victimization among Taiwanese Students in Special Schools. Routledge Taylor \& Francis Group. International Journal of Disability, Development and Education, 33(2), 246. https://doi.org/10.1080/1034912X.2015.1092505

Williford, Anne, Boulton, Aaron, et al. (2016). The Effect of Bullying and Victimization on Cognitive Empathy Development During the Transition to Middle School. Child and Youth Care Forum, 45(4). https://doi.org/10.1007/s10566-015-9343-9

Wong, Ching, Cheng, Ying, et al. (2013). Multiple Perspectives on the Targets and Causes of School Bullying. Routledge Taylor \& Francis Group. Educational Psychology in Practice, 29(3). https://doi.org/10.1080/02667363.2013.837030

Yahya, Hyder, Hashim, Mushtaq, et al. (2015). Bullying victimization among school- going adolescents in Iraq. J. Fa. Med. Baghdad, 57(3). https://doi.org/10.32007/med.1936/jfacmedbagdad.v57i3.10

Zaghalil, Ahmad, Al-Matarneh, Khawlah. (2011). Relationship between psychological stresses and rebellion among adolescents in accordance with class, gender and educational level of their Parents. MUTAH LIL -BUHUTH WAD-DIRASAT - HUMANITIES AND SOCIAL SCIENCES SERIES, Jordan, 26(5), 251.

\section{Copyrights}

Copyright for this article is retained by the author(s), with first publication rights granted to the journal.

This is an open-access article distributed under the terms and conditions of the Creative Commons Attribution license (http://creativecommons.org/licenses/by/3.0/). 